\title{
Carbon nano-fiber based membrane reactor for selective nitrite hydrogenation
}

Roger Brunet Espinosa ${ }^{a}$, Damon Rafieian ${ }^{b}$, Rob G.H. Lammertink ${ }^{c}$ and Leon Lefferts ${ }^{d *}$

${ }^{a}$ Catalytic Processes and Materials group, Faculty of Science and Technology, MESA+ Institute for Nanotechnology, University of Twente, PO Box 217, 7500 AE Enschede, The Netherlands, r.brunetespinosa@utwente.nl

${ }^{\mathrm{b}}$ Soft Matter, Fluidics and Interfaces group, Faculty of Science and Technology, MESA+ Institute for Nanotechnology, University of Twente, PO Box 217, 7500 AE Enschede, The Netherlands, d.rafieianboroujeni@utwente.nl

' Soft Matter, Fluidics and Interfaces group, Faculty of Science and Technology, MESA+ Institute for Nanotechnology, University of Twente, PO Box 217, 7500 AE Enschede, The Netherlands, r.g.h.lammertink@utwente.nl

d Catalytic Processes and Materials group, Faculty of Science and Technology, MESA+ Institute for Nanotechnology, University of Twente, PO Box 217, 7500 AE Enschede, The Netherlands, I.lefferts@utwente.nl

*Corresponding author (Leon Lefferts)

Highlights:

- Fabrication of a membrane reactor for the nitrite hydrogenation

- Reactor layout allows low hydrogen concentrations in the reaction zone

- Manipulation of the $\mathrm{H} / \mathrm{N}$ ratio on the catalyst surface

- Higher selectivity towards nitrogen than other reactor layouts

Keywords:

Nitrite hydrogenation, membrane reactor, ammonia selectivity, $\mathrm{H} / \mathrm{N}$ ratio, carbon nano-fibers, $\mathrm{Pd}$ 


\section{Abstract:}

Catalytic hydrogenation of nitrite in drinking water demands control over the selectivity towards nitrogen, minimizing the formation of ammonia. This selectivity is strongly influenced by the $\mathrm{H} / \mathrm{N}$ ratio of reaction intermediates at the catalyst surface. Therefore, we fabricated a membrane reactor that feeds separately hydrogen gas and a nitrite solution. This allows dosing low but homogeneous hydrogen concentrations along the axial direction of the catalyst bed. As a consequence, low $\mathrm{H} / \mathrm{N}$ ratios can be achieved, favouring the formation of nitrogen without limiting the nitrite conversion. We demonstrate that this reactor concept offers better nitrogen selectivity than conventional reactor configurations where hydrogen is pre-dissolved in the nitrite solution. 


\section{Introduction:}

During the last few decades, the use of microreactors for chemical conversion and analysis has experienced spectacular advances. With these miniaturized reaction systems, it is possible to explore wider pressure, temperature and concentration ranges as compared to conventional macroscopic reactors. Due to their small characteristic length, microreactors exhibit a high surface to volume ratio, where surface active forces dominate volume forces. This entails an enhancement in mass and heat transport that can improve activity and selectivity because the local concentrations and temperature at the active sites can be better controlled. Additionally, the small volume of the microreactors allows a safer operation, especially for the formation of hazardous and toxic chemicals [1-8].

Suppression of heat and mass transfer limitations in microreactors makes them ideal for three phase catalytic reactions. These reactions generally suffer from transport limitations caused, for example, by stagnant film resistance at the external surface area of the solid catalyst and internal diffusion in porous catalyst bodies. These effects are more prominent when the reactions are fast. To minimize resistance at the gas-liquid interface, a good dispersion of the gas in the liquid is required. This can be achieved via the use of membrane microreactors [6-10].

Micro/macro membrane reactors are usually divided in three categories, namely extractors, distributors and contactors. Extractors selectively remove a product of an equilibrium-restricted reaction to obtain higher yields as compared to conventional reactors. Distributors allow dosing the gas reactant along the reaction zone generating an optimum concentration profile. This becomes important for reaction networks where side reactions are strongly influenced by the concentration of one of the reactants. Contactors present a catalytic membrane, creating a well-defined reaction interface between two different medias [11-15].

Nitrite $\left(\mathrm{NO}_{2}{ }^{-}\right)$and nitrate $\left(\mathrm{NO}_{3}{ }^{-}\right)$hydrogenation are fast liquid phase reactions that can benefit from micro-membrane technology [16-19]. These compounds are typical water contaminants that can lead to health problems. Although nitrate is not directly harmful for humans, it can be converted in the 
body to nitrite via reduction processes leading to health diseases such as methemoglobinemia (blue baby syndrome) or to the formation of carcinogenic nitrosamines [20-25]. A very efficient way to remove nitrite is via catalytic hydrogenation [26]. This reaction converts nitrite to nitrogen and ammonia $\left(\mathrm{NH}_{4}{ }^{+}\right.$, by-product). European Environment Agency (EEA) established a maximal ammonia concentration in water of $0.5 \mathrm{mg} / \mathrm{L}$ [27]. Therefore, significant efforts focus on the prevention of ammonia formation. The selectivity of nitrite hydrogenation is influenced by various parameters such as temperature, $\mathrm{pH}$ and the $\mathrm{H} / \mathrm{N}$ ratio of reactant intermediates at the catalyst surface. This last parameter can be tuned by regulating the concentration of the reactants (nitrite and hydrogen). Higher $\mathrm{H} / \mathrm{N}$ ratios will lead to higher ammonia selectivity while low ratios would lead to higher nitrogen selectivity [22, 27-30]. However, low hydrogen concentrations could also generate mass transfer limitations, resulting in low efficient use of the catalyst and consequently very low activity.

In the current work, we explore the use of a distributor membrane reactor for the nitrite hydrogenation reaction. This reactor consists of a hollow alumina structure partly filled with carbon nano-fibers (CNFs) loaded with palladium nanoparticles. The outer structure is covered with a polydimethylsiloxane (PDMS) membrane. This reactor can regulate the hydrogen dosed in the reaction zone by hydrogen dilution with argon to achieve low $\mathrm{H} / \mathrm{N}$ ratios. The reactor configuration allows low and homogeneous hydrogen concentration along the catalyst bed, preventing hydrogen depletion since hydrogen is continuously supplied through the membrane. Although membrane reactors have been studied for nitrate and nitrite hydrogenation [18, 19, 31-33], tuning of the selectivity via manipulation of the $\mathrm{H} / \mathrm{N}$ ratio has not yet been demonstrated. Operation at low $\mathrm{H} / \mathrm{N}$ ratio with nitrite solution pre-saturated with hydrogen would not be efficient, as exhaustion of dissolved hydrogen would cause very low nitrite conversion.

\section{Experimental:}

\subsection{Reagents and Materials}


Porous ceramic $\alpha$-alumina $\left(\alpha-\mathrm{Al}_{2} \mathrm{O}_{3}\right)$ hollow fibers with a mean pore size of $800 \mathrm{~nm}$ were obtained from Hyflux CEPAration Technologies, Europe. These hollow fibers have an inner and outer diameter of 0.9 and $1.9 \mathrm{~mm}$ respectively and were cut in pieces $55 \mathrm{~mm}$ long. They were used as catalyst support and at the same time used to construct the reactor. Nickel was deposited using nickel nitrate hexahydrate (Merck), urea (Merck) and nitric acid (65\%, Merck). CNFs were grown using ethylene (99.95\% PRAXAIR), hydrogen and nitrogen (99.999\% INDUGAS) without any further purification. Palladium was deposited using palladium acetylacetonate (Alfa Aesar) and toluene (> 99.9\%, Merck). PDMS coating was performed using toluene (>99.9\% Merck) as solvent and a two component PDMS RTV 615 kit (Permacol B.V.) consisting of a vinyl terminated pre-polymer and a Pt-catalyzed cross-linker named RTV-A and RTV-B respectively. The catalytic tests were performed using sodium nitrite (>99\%, Merck) as nitrite source.

\subsection{Fabrication of the reactors}

The synthesis of the membrane reactors consisted of several steps. Initially, nickel was deposited in the macropores of the alumina hollow fiber, followed by CNF growth. Any loose CNFs were removed by sonication. In the next step, palladium was deposited on the CNFs and then was calcined and reduced. Finally, the outer wall of the alumina fiber was coated with a viscous PDMS solution, forming a dense layer after curing. Several parameters of the process were studied to optimize the reactor (shown in table 1).

Nickel deposition: Homogeneous deposition-precipitation technique was used to deposit nickel on the walls of the macropores of the hollow alumina fiber. The hollow fibers were immersed asreceived in a stirred nickel nitrate solution of $80 \mathrm{~mL}$. Several concentrations were used: $0.02,0.2,1.0$ and $5.0 \mathrm{~g} \mathrm{Ni} / \mathrm{L}$. The temperature was kept constant at $100{ }^{\circ} \mathrm{C}$ and a reflux system was connected to avoid evaporation of the water. The initial $\mathrm{pH}$ of the solution was adjusted at $\mathrm{pH}=3.5 \mathrm{using}$ a diluted nitric acid solution. To precipitate the nickel on the alumina, $20 \mathrm{ml}$ of concentrated urea solution (1.06 $\mathrm{g} / 20 \mathrm{ml}$ ) were added drop-wise during the first 15 minutes. After $2 \mathrm{~h}$ of deposition time, the sample 
was removed from the nickel solution, rinsed thoroughly with miliQ water and dried at $85{ }^{\circ} \mathrm{C}$ during 2 $\mathrm{h}$ in vacuum.

CNF growth: Catalytic chemical vapour deposition technique was used to grow CNFs from the nickel particles deposited in the previous step. The synthesis of the CNFs was performed using an inhouse build quartz tube reactor with an inner diameter of $10 \mathrm{~mm}$. The hollow fiber was reduced in a mixture of $20 \% \mathrm{H}_{2}$ and $80 \% \mathrm{~N}_{2}$ for $2 \mathrm{~h}$ at different temperatures $\left(450,550,750\right.$ or $850{ }^{\circ} \mathrm{C}$ ) to vary the nickel particle size. The temperature was raised from $20^{\circ} \mathrm{C}$ to the target temperature at $6{ }^{\circ} \mathrm{C} / \mathrm{min}$ under $100 \mathrm{ml} / \mathrm{min}$ of $\mathrm{N}_{2}$. After the reduction, the system was cooled down in $80 \mathrm{ml} / \mathrm{min} \mathrm{N}_{2}$ flow to the CNF synthesis temperature $\left(350,450,550,600,700,750^{\circ} \mathrm{C}\right)$. The CNF synthesis was performed during 30 min with a gas mixture containing $7 \% \mathrm{H}_{2}, 20 \%$ ethylene $\left(\mathrm{C}_{2} \mathrm{H}_{4}\right)$ and $73 \% \mathrm{~N}_{2}$ with a total flow rate of 100 $\mathrm{ml} / \mathrm{min}$. Finally, the system was cooled down in nitrogen flow rate of $80 \mathrm{ml} / \mathrm{min}$.

In the last step, the sample was sonicated in miliQ water for 30 min to remove any CNFs poorly attached to the alumina fiber. After this treatment, the sample was dried at $85^{\circ} \mathrm{C}$ during $2 \mathrm{~h}$ in vacuum.

Pd deposition: A solution of palladium acetylacetonate in toluene with a concentration of $6 \mathrm{mg}$ $\mathrm{Pd} / \mathrm{ml}$ was prepared for depositing palladium. The hollow fiber with CNFs was immersed in $25 \mathrm{ml}$ of the prepared solution for $17 \mathrm{~h}$. Next, it was removed from the solution and dried during $2 \mathrm{~h}$ at $85^{\circ} \mathrm{C}$ in vacuum. In the next step, the sample was oxidized in air for $1 \mathrm{~h}$ at $250^{\circ} \mathrm{C}$ and reduced for $2 \mathrm{~h}$ in a gas mixture of $50 \% \mathrm{H}_{2}$ and $50 \% \mathrm{~N}_{2}$ also at $250{ }^{\circ} \mathrm{C}$. Finally the system was cooled down to room temperature in nitrogen flow.

PDMS coating: Adapted from Aran et al. [19], a two component PDMS kit (RTV-A and RTV-B, 10:1 weight ratio) was dissolved in toluene at $85 \mathrm{wt} \%$ and heated at $60^{\circ} \mathrm{C}$ in a home-made reflux setup for pre-crosslinking the PDMS/toluene solution. The viscosity of the solution was measured by a Brookfield DV-II + Pro viscometer equipped with a $\mathrm{nr}-61$ spindle. When a viscosity of $100 \mathrm{mPa} . \mathrm{s}$ was reached, the cross-linking was stopped by immersing the solution in ice. The hollow alumina fiber was dip-coated 
with the partially cross-linked solution at a constant speed of $2.5 \mathrm{~mm} / \mathrm{s}$. To prevent the presence of PDMS inside the alumina fiber, one end of the alumina was sealed by glue and the open end was kept above the PDMS solution during the coating. In the last step, the coated sample was completely crosslinked in an oven at $80^{\circ} \mathrm{C}$ for $2 \mathrm{~h}$. Finally, both ends of the alumina were cut to remove the glue at one side and the non-coated part at the other side.

\subsection{Catalytic test}

The membrane reactor, named ' $\mathrm{H}_{2}$ outside', was tested for the nitrite hydrogenation to assess its performance in a fast liquid phase reaction. The performance of this reactor was compared with two other reactor layouts (' $\mathrm{H}_{2}$ inside' and 'Packed bed'), as described in detail in sections 2.3.1., 2.3.2. and 2.3.3. All reactions were carried in liquid phase at $20^{\circ} \mathrm{C}$. Inlet and outlet concentrations of nitrite and ammonia were measured with an in-line Ion Chromatograph (Dionex, ICS 1000) from which nitrite conversion and ammonia selectivity were calculated according to equation 1 and 2 respectively. It was assumed that nitrogen and ammonia are the only products $[23,27,29]$, calculating nitrogen selectivity based on the mass balance. The liquid flow rate was varied between 0.1 and $3 \mathrm{ml} / \mathrm{min}$ and the gas flow rate between 100 and $200 \mathrm{ml} / \mathrm{min}$ keeping the hydrogen partial pressure between 0.04 and 1.00 bar (balanced with Ar). Experiments were done under similar nitrite conversions to allow comparing selectivities of the different reactor layouts. In all cases, the solutions were not buffered.

$\mathrm{NO}_{2}^{-}$conversion $=\left(\left[\mathrm{NO}_{2}^{-}\right]_{\text {initial }}-\left[\mathrm{NO}_{2}^{-}\right]_{\text {final }}\right) /\left[\mathrm{NO}_{2}^{-}\right]_{\text {initial }} * 100$

(Equation 1)

$\mathrm{NH}_{4}{ }^{+}$selectivity $=\left(\left[\mathrm{NH}_{4}^{+}\right]_{\text {final }}-\left[\mathrm{NH}_{4}{ }^{+}\right]_{\text {initial }}\right) /\left(\left[\mathrm{NO}_{2}{ }^{-}\right]_{\text {initial }}-\left[\mathrm{NO}_{2}{ }^{-}\right]_{\text {final }}\right) * 100$

(Equation 2)

\subsection{1. 'H $H_{2}$ outside' layout}

This reactor layout embodies the membrane reactor designed to supply low and homogeneous hydrogen concentrations throughout the axial direction of the catalyst bed. The liquid containing nitrite is fed into the tube of the hollow membrane reactor while the gas is fed to the shell of the 
reactor and is allowed to diffuse through the PDMS membrane coated on the outer wall of the reactor tube (figure 2a). Hydrogen and nitrite are expected to meet and react in the macropores of the $\alpha-\mathrm{Al}_{2} \mathrm{O}_{3}$ where palladium is deposited on entangled CNFs. In all experiments, liquid is saturated in argon to remove oxygen and other gases present in ambient which could interfere with the reaction. The liquid flow rate used was always $0.2 \mathrm{ml} / \mathrm{min}$ with a nitrite concentration between 20 and $1000 \mu \mathrm{mol} / \mathrm{L}$. The gas flow rate was supplied at 1 bar, feeding a mixture of hydrogen and argon with the hydrogen partial pressure varied between 0.05 and 1 bar.

\subsection{2. ' $\mathrm{H}_{2}$ inside' layout}

The reactor used for this layout was physically the same as for ' $\mathrm{H}_{2}$ outside'. However, it was operated differently. In this design, the liquid containing nitrite was pre-saturated with hydrogen at 1 bar and fed inside the tube of the hollow membrane reactor. Pure argon was supplied at 1 bar to the reactor shell to avoid any permeation of air to the reaction zone (figure $2 \mathrm{~b}$ ). The liquid flow rate was $0.2 \mathrm{ml} / \mathrm{min}$ with a nitrite and hydrogen concentrations of $220 \mu \mathrm{mol} / \mathrm{L}$ and $780 \mu \mathrm{mol} / \mathrm{L}$ respectively. Hydrogen concentration in the liquid feed was controlled by the pressure of the hydrogen used to saturate the nitrite solution and was calculated based on Henry's law constant (7.7 mol. $\left.\mathrm{m}^{-3} \cdot \mathrm{Pa}^{-1},[34]\right)$.

\subsection{3. 'Packed bed' layout}

A membrane reactor without any PDMS coating was crushed and sieved to the size of $0.5 \mathrm{~mm}$ particles and was tested as a packed bed reactor. The reactor was fed with a nitrite solution presaturated in hydrogen at 1 bar (figure 2c). The liquid flow rate was $3 \mathrm{ml} / \mathrm{min}$ to obtain the same nitrite conversion as compared to the other reactor layouts. Additionally, one experiment was performed with a low flow rate $(0.4 \mathrm{ml} / \mathrm{min})$. Nitrite and hydrogen concentrations were kept at $220 \mu \mathrm{mol} / \mathrm{L}$ and $780 \mu \mathrm{mol} / \mathrm{L}$ respectively. 


\subsection{Characterization}

The samples were sonicated for 30 min to test the mechanical stability of the grown CNFs and to remove the poorly attached CNFs. The BET surface area of the hollow alumina fibers after CNF growth was calculated from $\mathrm{N}_{2}$-adsorption isotherm obtained at $77 \mathrm{~K}$ (Micromeritics Tristar). The morphology of the synthesized membrane reactors was studied with Scanning Electron Microscopy, HR-SEM (Analysis Zeiss MERLIN HR-SEM). The properties studied include the CNF diameter, the nickel particle size and the thickness of the PDMS layer. Cross-sections were prepared by cutting the samples with a scalpel. CNF diameter and nickel particle size (before CNF growth) were determined based on the average of 200 measurements on five different positions in the sample. The HR-SEM was equipped with Energy Dispersive X-Ray analysis system, EDX (Oxford Instruments X-Max80 EDX), allowing to study the distribution of nickel and carbon in the axial direction of the membrane reactor. The amount of carbon grown in the macropores of the $\alpha-\mathrm{Al}_{2} \mathrm{O}_{3}$ was measured with an analytical balance by weighing the sample before and after CNF growth. Additionally, also elemental analysis, EA (Elemental Analyser Inter Science Flash 2000) was used to determine the amount of carbon deposited on the $\alpha$ $\mathrm{Al}_{2} \mathrm{O}_{3}$. The average pore size and the void fraction of the $\alpha-\mathrm{Al}_{2} \mathrm{O}_{3}$ before the CNF growth were determined with $\mathrm{Hg}$ porosimetry (Quantachrome Poremaster PM33). The percentage of pore volume filled with CNFs was calculated from the void fraction of the $\alpha-\mathrm{Al}_{2} \mathrm{O}_{3}$ and the amount of CNFs. The Pd loading on the membrane reactor was determined with X-ray fluorescence spectroscopy, XRF (Philips PW 1480).

\section{Results}

Figure 3 shows a cross-sectional view of the $\alpha-\mathrm{Al}_{2} \mathrm{O}_{3}$ hollow fiber as-received, presenting large pore sizes of $800 \mathrm{~nm}$ which is in agreement with the specifications of the manufacturer. The porosity of the 
material, measured with $\mathrm{Hg}$ porosimetry is $0.13 \mathrm{~cm}^{3} / \mathrm{g}$ and the BET surface area is typically $0.1 \mathrm{~m}^{2} / \mathrm{g}$ [18].

Three parameters were optimized for the synthesis of the membrane reactor: nickel concentration, reduction temperature and CNF growth temperature. The goal was to obtain a material with a high surface area, determined from BET measurements. However, to prevent mass transfer limitations, the material should maintain an open structure with a relatively low fraction of alumina pore volume filled with CNFs (assessed with Hg porosimetry) and present curly and entangled CNFs (imaged with HRSEM). Finally, the CNFs should be distributed homogeneously in the porous alumina as judged with HRSEM. All information related with the prepared samples can be found in table 1.

\subsection{Nickel deposition}

Figure 4 shows cross-sections of the alumina hollow fibers, allowing the observation of the morphology of the CNFs inside the alumina macropores. All four samples were prepared using different concentrations of nickel precursor during the nickel deposition.

The sample prepared with a low nickel concentration $(0.02 \mathrm{~g} \mathrm{Ni} / \mathrm{L})$ has few CNFs partly covering the alumina walls. These CNFs can be observed in the bright spots on the alumina grains shown in figure $4 a$. The low carbon content of this sample $(0.2 \mathrm{wt} \%)$ leads to a very poor filling of the alumina macropores (approx. 0.6 vol\%) which results in a very low surface area of $0.4-0.5 \mathrm{~m}^{2} / \mathrm{g}$ (table 1 ). The sample prepared with a high nickel concentration (5.0 g Ni/L; figure 4d) presents a macroscopic CNF layer (black region) grown on the external surface of the alumina fiber (white region) with an irregular thickness around $200 \mu \mathrm{m}$. This massive CNF growth mechanically damages the alumina structure making it more brittle, in agreement with previous work [35]. Moreover, this irregular and highly porous CNF layer is not beneficial for applying a thin PDMS layer free of defects. Therefore, these two samples were not suitable for the purpose of this study. 
The samples prepared with $0.2 \mathrm{~g} \mathrm{Ni} / \mathrm{L}$ and $1.0 \mathrm{~g} \mathrm{Ni} / \mathrm{L}$ present a satisfactory CNF coverage (figure $4 \mathrm{~b}$ and c). However, the $1.0 \mathrm{~g} \mathrm{Ni} / \mathrm{L}$ sample has the highest carbon content and presents the largest surface area (approx. $10 \mathrm{~m}^{2} / \mathrm{g}_{\text {sample }}$ ) combined with a modest filling of the macropores (14.8 vol\%; table 1 ). Therefore, $1.0 \mathrm{~g} \mathrm{Ni} / \mathrm{L}$ was selected as the optimum nickel concentration and the other parameters were studied using this nickel concentration. 
Table 1: Properties of all samples with varying nickel amount, reduction temperature and CNF growth temperature. Only the relevant properties were measured for every sample.

\begin{tabular}{|c|c|c|c|c|c|c|c|c|c|}
\hline 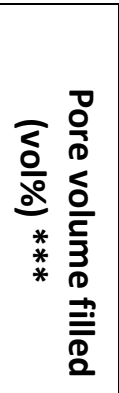 & 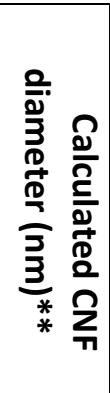 & 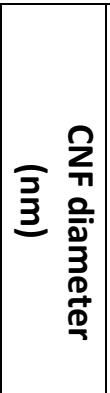 & 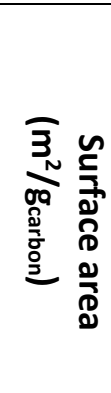 & 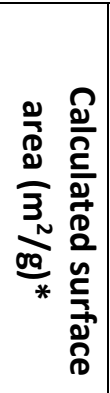 & 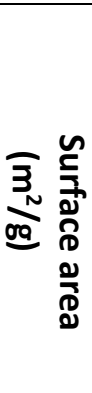 & $\begin{array}{l}\xi \\
\text { ò } \\
\text { n. }\end{array}$ & 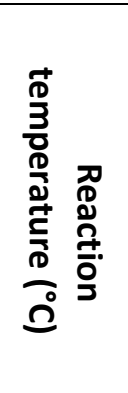 & 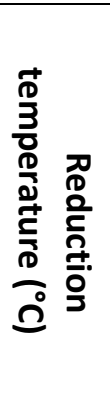 & 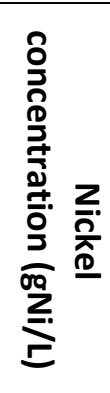 \\
\hline ì & ' & $\stackrel{\omega}{\omega}$ & & $\begin{array}{l}\stackrel{D}{\text { in }} \\
\text { in }\end{array}$ & , & $\stackrel{\circ}{\text { N }}$ & 鬲 & 㝕 & 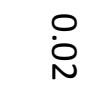 \\
\hline$\dot{H}$ & , & $\underset{\perp}{\omega}$ & & ü & ' & $\tilde{i}$ & जी & 㝕 & $\stackrel{\text { i }}{ }$ \\
\hline$\underset{\infty}{\stackrel{+}{+}}$ & , & $\underset{\sim}{\omega}$ & & $\begin{array}{l}\vec{\circ} \\
\text { in }\end{array}$ & ' & $\stackrel{u}{i}$ & 品 & 突 & $\dot{0}$ \\
\hline ' & , & ' & & ' & ' & $\dot{H}$ & 㤐 & 突 & بٓ \\
\hline$\stackrel{\vec{\omega}}{v}$ & ' & , & & ' & ' & $\stackrel{M}{i}$ & 突 & 突 & $\stackrel{\circ}{\circ}$ \\
\hline$\ddot{\omega}$ & $\underset{\infty}{\omega}$ & & $\stackrel{+}{\infty}$ & & $\stackrel{\vec{i}}{\dot{N}}$ & $\stackrel{\sim}{\sim}$ & जि & जু & $\stackrel{+}{\circ}$ \\
\hline$\underset{\infty}{\vec{\infty}}$ & ũ & & 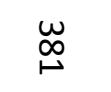 & & un & $\vec{v}$ & 㤐 & પે & $\stackrel{+}{\circ}$ \\
\hline$\stackrel{u}{i r}$ & $\stackrel{\circ}{0}$ & & $\stackrel{\omega}{\omega}$ & & $\underset{\triangleright}{u}$ & $\stackrel{\bullet}{v}$ & ज़ & $\begin{array}{l}\infty \\
\text { 心 }\end{array}$ & $\stackrel{\circ}{\circ}$ \\
\hline ' & ' & & & & ' & 이 & $\underset{\sim}{w}$ & $\begin{array}{l}\infty \\
\text { जI }\end{array}$ & $\stackrel{\circ}{\circ}$ \\
\hline$\stackrel{u}{\omega}$ & ô & & $\stackrel{\omega}{\omega}$ & & $\stackrel{u}{\Delta}$ & $\stackrel{\bullet}{v}$ & जI & $\begin{array}{l}\infty \\
\text { ஸ̆ }\end{array}$ & $\stackrel{\circ}{\circ}$ \\
\hline$\stackrel{\vec{N}}{\Delta}$ & $\ddot{0}$ & & $\underset{\infty}{\stackrel{\omega}{\infty}}$ & & $\stackrel{\sim}{\stackrel{\sim}{\circ}}$ & $\ddot{\sigma}$ & ज̆ & $\begin{array}{l}\infty \\
\text { 心 }\end{array}$ & $\dot{0}$ \\
\hline $\begin{array}{l}\tilde{n} \\
0\end{array}$ & $\stackrel{\infty}{\dot{\omega}}$ & เ & $\underset{\sim}{\sim}$ & $\begin{array}{l}\vec{w} \\
\dot{i r}\end{array}$ & $\begin{array}{l}\overrightarrow{6} \\
\infty\end{array}$ & ir & 8 & $\stackrel{\infty}{0}$ & $\stackrel{\circ}{\circ}$ \\
\hline$\underset{\dot{\omega}}{\vec{\omega}}$ & $\stackrel{\vec{i}}{i}$ & & 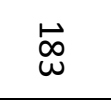 & & $\dot{0}$ & $\underset{\infty}{\omega}$ & ठั & $\begin{array}{l}\infty \\
\text { ஸ̆ }\end{array}$ & $\dot{\circ}$ \\
\hline ' & ' & & & & ' & Oे & जे & $\stackrel{\infty}{\stackrel{\infty}{0}}$ & G \\
\hline
\end{tabular}

* The calculated surface area, based on the diameter of the CNFs and the carbon loading $=4(\% \mathrm{C})$ / (CNF density x CNF diameter)

** Calculated CNF diameter, based on surface area and carbon loading $=4(\% \mathrm{C}) /(\mathrm{CNF}$ density $\mathrm{x}$ surface area) 
*** Pore volume filled, based on the carbon loading and the original pore volume determined with $\mathrm{Hg}$ porosimetry = (weight CNFs / CNF density) / (volume alumina pores)

In all the calculations, cylindrical CNFs with the same diameter are assumed, with a density equal to the density of graphite.

\subsection{Reduction temperature}

The morphology of the CNFs is strongly affected by the nickel particle size, which can be manipulated by the reduction temperature. Four different temperatures were tested followed by CNF synthesis at $450{ }^{\circ} \mathrm{C}$.

The different reduction temperatures induced significant differences in the morphology of the CNFs. When using low reduction temperatures $\left(550\right.$ and $\left.450^{\circ} \mathrm{C}\right)$, straight and very thin CNFs $(3.8 \mathrm{~nm}$ at $550{ }^{\circ} \mathrm{C}$, table 2) grow parallel next to each other, generating groups of packed CNFs that resemble amorphous carbon (figure $5 c$ and d). The resulting morphology, with very small pores between the packed CNFs, would not be very suitable as catalyst support.

In case of high reduction temperatures $\left(850\right.$ and $750{ }^{\circ} \mathrm{C}$ ), CNFs present slightly bigger diameter than at low reduction temperatures due to sintering of the nickel particles and exhibit smaller, but still significant, BET surface areas than at $550{ }^{\circ} \mathrm{C}$. However, high reduction temperatures are preferred since CNFs offer an open structure with curly and entangled CNFs (figure $5 a$ and b), reducing the risk of mass transfer limitations. Among the two high reduction temperatures, $850{ }^{\circ} \mathrm{C}$ was used as standard temperature for further optimization.

\section{3. $\quad$ CNF growth temperature}

The morphology of the CNFs can also be influenced by the temperature of the CNF growth. To optimize the growth temperature, six different temperatures were tested. All samples were synthesized using a concentration of $1.0 \mathrm{~g} \mathrm{Ni} / \mathrm{L}$ for the nickel deposition and a reduction temperature of $850^{\circ} \mathrm{C}$. 
CNFs were successfully grown at the reaction temperatures between 450 and $700{ }^{\circ} \mathrm{C}$ (figure $6 \mathrm{~b}$-e), where the highest $\mathrm{CNF}$ amount was obtained at $600{ }^{\circ} \mathrm{C}(7.5 \mathrm{wt} \%$; table 1$)$. Moreover, the surface area after growing CNFs at $600^{\circ} \mathrm{C}$ is significantly high $\left(16.8 \mathrm{~m}^{2} / \mathrm{g}\right.$; table 1$)$. Although the sample prepared at $550{ }^{\circ} \mathrm{C}$ has the highest surface area $\left(21.0 \mathrm{~m}^{2} / \mathrm{g}\right.$; table 1$)$ and relatively low pore filling $(17.2 \mathrm{vol} \%$; table 1) the morphology of the CNFs is not well-defined, with some areas containing densely packed CNFs, resembling the morphology of amorphous carbon (figure $6 \mathrm{~g}$ ). At $600^{\circ} \mathrm{C}$, the CNFs are homogeneously distributed and do not agglomerate forming packed areas (figure 6h). Therefore, $600{ }^{\circ} \mathrm{C}$ was selected as the optimum CNF growth temperature.

Nickel is not able to catalyze the formation of CNFs at the lowest CNF growth temperature (350 ${ }^{\circ} \mathrm{C}$ ), (figure 6a). Only a thin carbon layer appeared at the outer wall of the alumina fiber (figure $A 1$, Appendix A). At $350{ }^{\circ} \mathrm{C}$, the carbon dissolves in the nickel particles, which precipitates during the cooling, forming an amorphous layer that covers the nickel particles [36]. This phenomenon is especially visible at the outer wall of the alumina fiber because it has a higher nickel concentration and it is directly exposed to the gas flow. At the highest CNF growth temperature $\left(750^{\circ} \mathrm{C}\right)$, the CNF coverage was extremely low (figure 6f), showing only few long CNFs present at the internal surface of the alumina tube.

\subsection{Characterization of the optimal sample}

The optimal sample was characterized in more detail, including the Ni/alumina sample before the CNF growth. A homogeneous nickel distribution with an average particle size of $14.0 \mathrm{~nm}$ and an average CNF diameter of $10.0 \mathrm{~nm}$ were measured with HRSEM (figure A2 and A3, Appendix A). The estimation of CNF diameter based on HRSEM $(10.0 \mathrm{~nm})$ results in somewhat higher values than the CNF diameter estimated based on the surface area $(8.3 \mathrm{~nm}$, table 1$)$, which is probably due to the broad distribution and the difference in averaging (local number averaged from HRSEM, global surface area averaged from BET). The differences between nickel particle size and CNF diameter is probably 
caused by nickel fragmentation during CNF growth. The total amount of carbon grown is 7.5 wt\%, generating a total surface area of $16.8 \mathrm{~m}^{2} / \mathrm{g}$ (table 1), 2 orders of magnitude higher than the bare alumina. Carbon and nickel are both distributed homogeneously throughout the porous alumina. Only near the outer wall, an increase in both concentrations is measured by EDX (figure A4, Appendix A), likely, because the outer alumina wall is directly exposed to the nickel solution during nickel deposition, as well as to ethylene during CNF growth as compared to the pores inside the alumina tube [19].

After palladium deposition, a loading of $0.011 \mathrm{gPd} / \mathrm{gCNF}$ was measured with XRF. The palladium loading is reproducible within $5 \%$ variation. The dispersion of the palladium particles could not be determined with $\mathrm{H}_{2}$ or $\mathrm{CO}$ chemisorption because nickel is present in significantly higher concentrations than palladium, influencing any chemisorption of $\mathrm{CO}$ and $\mathrm{H}_{2}$.

A SEM image of a cross-section of the sample after PDMS coating is shown in figure 7. The PDMS thickness observed was $10 \pm 2 \mu \mathrm{m}$ and is homogeneous in both axial and radial direction. The PDMS layer exhibits excellent mechanical stability and was still intact after $400 \mathrm{~h}$ time-on-stream.

\subsection{Catalytic nitrite hydrogenation}

The three reactor layouts described in the experimental section (' $\mathrm{H}_{2}$ outside', ' $\mathrm{H}_{2}$ inside' and 'Packed bed') were tested for nitrite hydrogenation. All reactors were synthesized identically and therefore, presented the same properties.

Figure 8 shows that at comparable nitrite conversion levels, ' $\mathrm{H}_{2}$ outside' layout results in the lowest ammonia selectivity as compared to ' $\mathrm{H}_{2}$ inside' and 'Packed bed' layouts. The selectivity to ammonia in the 'packed bed' layout remains unchanged when varying the liquid flow rate between 3.0 and 0.4 $\mathrm{ml} / \mathrm{min}$, which is equivalent to variation of the weight hourly space velocity (nitrite solution flow weight per hour/ catalyst weight loaded in the reactor, WHSV) between 5.19 and $0.69 \mathrm{~h}^{-1}$ (figure $8 \mathrm{c}$ and d respectively). 
Figure 9 presents the influence of the hydrogen concentration in the gas feed for the ' $\mathrm{H}_{2}$ outside' layout. WHSV as well as nitrite concentration were kept constant. The nitrite conversion level hardly changes with hydrogen concentration, except at low concentrations, whereas selectivity to ammonia strongly increases with increasing hydrogen pressure throughout the concentration window.

Figure 10 shows that ammonia selectivity decreases with increasing nitrite concentration keeping hydrogen concentration constant. Note that these experiments were performed under different flow rates, attempting to keep the nitrite conversion level as constant as possible, close to differential conditions.

\section{Discussion}

\subsection{Optimization of the membrane reactor properties}

After optimization of the fabrication parameters, it was found that $1 \mathrm{~g} \mathrm{Ni} / \mathrm{L}$, a reduction temperature of $850{ }^{\circ} \mathrm{C}$ and a $\mathrm{CNF}$ growth temperature of $600{ }^{\circ} \mathrm{C}$ lead to the optimum membrane reactor properties. The pore filling obtained indicates that the porosity of the membrane reactor is only 25 vol\% less than the porosity of the original alumina fiber while the surface area increased two orders of magnitude (from 0.1 to $16.8 \mathrm{~m}^{2} / \mathrm{g}$ ). A comparable surface area was obtained by Aran et al. [19] with hollow stainless steel fibers loaded also with CNFs. High pore fillings are detrimental since small pores will completely fill and crack, breaking the internal structure of the alumina fiber [35] and making the reactor more brittle. The CNF morphology and distribution through the material is also crucial. Somewhat thicker CNFs $(10 \mathrm{~nm})$ are preferred because these form an open structure with entangled CNFs, whereas thinner CNFs (3-4 nm), as a result of low reduction temperature, form too dense layers of packed CNFs. Confinement of the CNFs inside the alumina wall is preferred to avoid a macroscopic CNF layer at the outer alumina wall that would complicate the coating of a thin and defect free PDMS layer. 


\subsection{Effect of reactor design on ammonia selectivity}

' $\mathrm{H}_{2}$ outside' layout is more selective towards nitrogen than the other two layouts. It produces almost three times less ammonia at comparable nitrite conversion levels (figure 8). These differences in selectivities are attributed to differences in local concentrations at the palladium active sites.

' $\mathrm{H}_{2}$ outside' layout operates at lower $\mathrm{H} / \mathrm{N}$ ratios than the other layouts. The hydrogen partial pressure in the reactor shell is 0.2 bar, corresponding to $156 \mu \mathrm{mol} \mathrm{H} / \mathrm{L}$ in the liquid according to the hydrogen solubility. However, the actual hydrogen concentration is even lower because of the diffusion resistance of the PDMS layer for hydrogen transport from the shell to the reaction zone. ' $\mathrm{H}_{2}$ inside' and 'Packed bed' operate both at $780 \mu \mathrm{mol} \mathrm{H} \mathrm{H}_{2} / \mathrm{L}$ via pre-saturation, providing $\mathrm{H} / \mathrm{N}$ ratios more than five times higher than ' $\mathrm{H}_{2}$ outside'. Low $\mathrm{H} / \mathrm{N}$ ratios cannot be achieved with ' $\mathrm{H}_{2}$ inside' and 'Packed bed' due to hydrogen depletion. Operation at $156 \mu \mathrm{mol} \mathrm{H}_{2} / \mathrm{L}$, would lead to a maximum nitrite conversion of only $30 \%$ and to very low reaction rates as a result of hydrogen depletion.

Figure 9 illustrates that the hydrogen concentration is strongly influencing the selectivity of the reaction. Moreover, figure 10 shows that the nitrite concentration also strongly influences the selectivity. This confirms that the $\mathrm{H} / \mathrm{N}$ ratio plays a crucial role in determining the selectivity of the reaction. This membrane reactor allows manipulation of this ratio and therefore, to tune the selectivity towards nitrogen.

This agrees well with literature, where it is claimed that by decreasing the $\mathrm{H} / \mathrm{N}$ ratio, the selectivity towards ammonia can be decreased $[27-29,37,38]$. This can be easily understood, based on the stoichiometry of the reactions to nitrogen and ammonia (equations 3 and 4 respectively), indicating that more hydrogen is needed to form ammonia as compared to nitrogen.

$$
\begin{array}{lll}
2 \mathrm{NO}_{2}{ }^{-}+3 \mathrm{H}_{2}+2 \mathrm{H}^{+} \stackrel{\mathrm{Pd}}{\longrightarrow} \mathrm{N}_{2}+4 \mathrm{H}_{2} \mathrm{O} & \text { (Equation 3) } \\
\mathrm{NO}_{2}{ }^{-}+3 \mathrm{H}_{2}+2 \mathrm{H}^{+} \stackrel{\mathrm{Pd}}{\longrightarrow} \mathrm{NH}_{4}^{+}+2 \mathrm{H}_{2} \mathrm{O} & \text { (Equation 4) }
\end{array}
$$


A similar reactor concept was tried by Aran et al. [18] who used a hollow alumina fiber with an

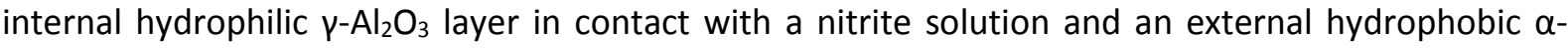
alumina layer in contact with the gas, acting as membrane. Although the authors varied the hydrogen concentration from $5 \%$ to $100 \%$, no significant difference in ammonia formation was observed under similar experimental conditions. This is attributed to the almost inexistent diffusion resistance at the gas-liquid interface at the non-wetting hydrophobic $\alpha-\mathrm{Al}_{2} \mathrm{O}_{3}$ macropores. The high diffusivity coefficient of hydrogen in gas phase (typically $1 \mathrm{~cm}^{2} / \mathrm{s}$ ) [39] allows easy access of hydrogen to the reaction zone for all tested conditions. Instead, the low diffusivity coefficient of hydrogen in PDMS (close to $10^{-4} \mathrm{~cm}^{2} / \mathrm{s}$ ) [40] creates a higher gas diffusion resistance making the selectivity more sensitive to changes in hydrogen concentration. In another attempt by Aran et al. [19], a porous stainless steel hollow fiber was used, partially filled with CNF, covered with a PDMS membrane, very similar to this work. Unfortunately, results cannot be compared because the performance of the reactor of Aran et al. [19] was importantly influenced by stoichiometric conversion of nitrite by iron particles, which formed during CNF synthesis on stainless steel.

\subsection{Activity and hydrogen reaction order for ' $\mathrm{H}_{2}$ outside'}

Although the change in selectivity is remarkably pronounced when varying the hydrogen concentration, the activity remains almost the same, especially in the range $20-100 \% \mathrm{H}_{2}$ (figure 9 ). This means that the hydrogen concentration influences selectivity much more than the reaction rate. The small variation in nitrite conversion when varying the hydrogen concentration indicates a low apparent reaction order for hydrogen (0.3, figure $A 5$, Appendix $A)$. It should be noted that this is indeed just an apparent order because concentration gradients through the wall of the membrane reactor, as schematically shown in figure 11 , will influence the apparent kinetics significantly. This will be discussed in detail in a subsequent paper. Nevertheless, similar low reaction orders are reported in literature for Pd-Cu/C [38] and Pd-CNF-Ni foam ('hairy' foam) [29]. Even zero-order is reported for Pd on carbon cloth [41]. 


\subsection{Performance of 'Packed bed'}

' $\mathrm{H}_{2}$ outside' layout exhibits the same reaction rate than ' $\mathrm{H}_{2}$ inside' but much lower than 'Packed bed'. Table 2 shows that 'Packed bed' layout has a much higher weight hourly space velocity (WHSV) than ' $\mathrm{H}_{2}$ outside' and ' $\mathrm{H}_{2}$ inside' when all the layouts present the same nitrite conversion (4-5\%). The two experiments performed with the 'Packed bed' layout showed that at low liquid flow rate (high nitrite conversion) the reaction rate is lower than at high liquid flow rate (low nitrite conversion). This is probably caused by a deviation from differential conditions, where at higher nitrite conversion, averaged nitrite and hydrogen concentrations decrease, generating lower rates.

Table 2: Nitrite conversion, WHSV and reaction rate for the experiments shown in figure 8; note that the amount of Pd is identical in all three cases

\begin{tabular}{|c|c|c|c|c|}
\hline & $\mathrm{H}_{2}$ outside & $\mathrm{H}_{2}$ inside & Packed bed (1) & Packed bed (2) \\
\hline Nitrite conversion (\%) & 4.8 & 4.1 & 4.2 & 24.9 \\
\hline WHSV $\left(\mathrm{h}^{-1}\right)$ & 0.35 & 0.35 & 5.19 & 0.69 \\
\hline Reaction rate $(\mathrm{mmol} / \mathrm{min})$ & $2.1 \times 10^{-6}$ & $1.8 \times 10^{-6}$ & $2.7 \times 10^{-5}$ & $2.2 \times 10^{-5}$ \\
\hline
\end{tabular}

The difference in reaction rate between 'Packed bed' and the other layouts could be caused by a significant by-passing of the reactants in the ' $\mathrm{H}_{2}$ inside' and ' $\mathrm{H}_{2}$ outside' layouts. The low flow rates used for the experiments result in a laminar flow (Reynolds number is 283). Obviously, this will result in much more tunnelling of liquid feed without interacting with the catalyst as compared to a packed bed geometry. Furthermore, the geometrical surface area between liquid and solid is lower for ' $\mathrm{H}_{2}$ outside' and ' $\mathrm{H}_{2}$ inside' than for 'Packed bed'. The $0.5 \mathrm{~mm}$ particles in the 'Packed bed' layout create an external contact area one order of magnitude higher than the inner alumina wall of ' $\mathrm{H}_{2}$ outside' and ' $\mathrm{H}_{2}$ inside' layouts.

Assuming some internal mass transfer limitations for all three layouts (Weisz-Prater criterion $\left(C_{W P}\right)$ for hydrogen and nitrite are 0.6 and 1.5 respectively for the 'Packed bed' layout at high liquid flow rate; equation B1, Appendix B), this increase in geometrical surface area will offer a larger fraction 
of accessible catalyst and therefore, higher activity. The relatively low $C_{W P}$ are caused by the low amount of palladium catalyst $(0.08 \mathrm{wt} \% \mathrm{Pd})$.

' $\mathrm{H}_{2}$ inside' and 'Packed bed' present the same high ammonia selectivity since both operate at the same high $\mathrm{H} / \mathrm{N}$ ratio. The ammonia selectivity seems independent of the nitrite conversion level in the $5-25 \%$ range (figure $8 \mathrm{c}$ and $\mathrm{d}$ ) confirming that consecutive reactions are not involved.

\section{Conclusions}

A membrane reactor that allows low and homogeneous hydrogen concentrations in the axial direction has been successfully synthesized. Experimental variables of Ni deposition and CNF growth were optimized, allowing manipulation of the selectivity in nitrite hydrogenation by establishing a low concentration of adsorbed hydrogen at the active sites. A comparison of different reactor layouts proved that this membrane reactor is 2-3 times more selective towards nitrogen, the desired product, at identical nitrite conversion levels. This membrane reactor shows that it is possible to manipulate the selectivity towards nitrogen, the desired product.

\section{Acknowledgments}

This work is supported by NanoNextNL, a micro and nanotechnology consortium of the Government of The Netherlands, and 130 partners. We are thankful to K. Altena - Schildkamp and M. Smithers for analysis, and B. Geerdink for designing the membrane reactor holder and for technical support. We also acknowledge Dr. H. C. Aran for fruitful discussions and for contributing to the reactor concept design. 


\section{References}

[1] A. Gavriilidis, P. Angeli, E. Cao, K.K. Yeong, Y.S.S. Wan, Technology and Applications of Microengineered Reactors, Chemical Engineering Research and Design, 80 (2002) 3-30.

[2] K.F. Jensen, Microreaction engineering - is small better?, Chemical Engineering Science, 56 (2001) 293-303.

[3] G.N. Doku, W. Verboom, D.N. Reinhoudt, A. van den Berg, On-microchip multiphase chemistry-a review of microreactor design principles and reagent contacting modes, Tetrahedron, 61 (2005) 2733-2742.

[4] P.L. Mills, D.J. Quiram, J.F. Ryley, Microreactor technology and process miniaturization for catalytic reactions-A perspective on recent developments and emerging technologies, Chemical Engineering Science, 62 (2007) 6992-7010.

[5] G. Chen, J. Yue, Q. Yuan, Gas-Liquid Microreaction Technology: Recent Developments and Future Challenges, Chinese Journal of Chemical Engineering, 16 (2008) 663-669.

[6] V. Hessel, P. Angeli, A. Gavriilidis, H. Löwe, Gas-Liquid and Gas-Liquid-Solid Microstructured Reactors: Contacting Principles and Applications, Industrial \& Engineering Chemistry Research, 44 (2005) 9750-9769.

[7] M.N. Kashid, L. Kiwi-Minsker, Microstructured Reactors for Multiphase Reactions: State of the Art, Industrial \& Engineering Chemistry Research, 48 (2009) 6465-6485.

[8] H.C. Aran, Porous ceramic and metallic microreactors, SFI, University of Twente, Enschede, 2011, pp. 126.

[9] G. Biardi, G. Baldi, Three-phase catalytic reactors, Catalysis Today, 52 (1999) 223-234.

[10] K.K. Sirkar, P.V. Shanbhag, A.S. Kovvali, Membrane in a Reactor: A Functional Perspective, Industrial \& Engineering Chemistry Research, 38 (1999) 3715-3737.

[11] R. Dittmeyer, V. Höllein, K. Daub, Membrane reactors for hydrogenation and dehydrogenation processes based on supported palladium, Journal of Molecular Catalysis A: Chemical, 173 (2001) 135184. 
[12] M. Huuhtanen, P.K. Seelam, T. Kolli, E. Turpeinen, R.L. Keiski, Advances in catalysts for membrane reactors, (2013) 401-432.

[13] S. Mota, S. Miachon, J.C. Volta, J.A. Dalmon, Membrane reactor for selective oxidation of butane to maleic anhydride, Catalysis Today, 67 (2001) 169-176.

[14] R. Dittmeyer, K. Svajda, M. Reif, A Review of Catalytic Membrane Layers for Gas/Liquid Reactions, Topics in Catalysis, 29 (2004) 3-27.

[15] A. Julbe, D. Farrusseng, C. Guizard, Porous ceramic membranes for catalytic reactors - overview and new ideas, Journal of Membrane Science, 181 (2001) 3-20.

[16] M. Vospernik, A. Pintar, G. Berčič, J. Batista, J. Levec, Potentials of Ceramic Membranes as Catalytic Three-Phase Reactors, Chemical Engineering Research and Design, 82 (2004) 659-666. [17] M. Vospernik, A. Pintar, G. Berčič, J. Levec, Experimental verification of ceramic membrane potentials for supporting three-phase catalytic reactions, Journal of Membrane Science, 223 (2003) 157-169.

[18] H.C. Aran, J.K. Chinthaginjala, R. Groote, T. Roelofs, L. Lefferts, M. Wessling, R.G.H. Lammertink, Porous ceramic mesoreactors: A new approach for gas-liquid contacting in multiphase microreaction technology, Chemical Engineering Journal, 169 (2011) 239-246.

[19] H.C. Aran, S. Pacheco Benito, M.W.J. Luiten-Olieman, S. Er, M. Wessling, L. Lefferts, N.E. Benes, R.G.H. Lammertink, Carbon nanofibers in catalytic membrane microreactors, Journal of Membrane Science, 381 (2011) 244-250.

[20] A. Pintar, G. Berčič, J. Levec, Catalytic liquid-phase nitrite reduction: Kinetics and catalyst deactivation, AIChE Journal, 44 (1998) 2280-2292.

[21] A. Pintar, Catalytic processes for the purification of drinking water and industrial effluents, Catalysis Today, 77 (2003) 451-465.

[22] D. Shuai, J.K. Choe, J.R. Shapley, C.J. Werth, Enhanced Activity and Selectivity of Carbon Nanofiber Supported Pd Catalysts for Nitrite Reduction, Environmental Science \& Technology, 46 (2012) 2847-2855.

[23] S. Hörold, K.D. Vorlop, T. Tacke, M. Sell, Development of catalysts for a selective nitrate and nitrite removal from drinking water, Catalysis Today, 17 (1993) 21-30.

[24] M. D'Arino, F. Pinna, G. Strukul, Nitrate and nitrite hydrogenation with Pd and Pt/SnO2 catalysts: the effect of the support porosity and the role of carbon dioxide in the control of selectivity, Applied Catalysis B: Environmental, 53 (2004) 161-168.

[25] A. Devard, M.A. Ulla, F.A. Marchesini, Synthesis of Pd/Al2O3 coating onto a cordierite monolith and its application to nitrite reduction in water, Catalysis Communications, 34 (2013) 26-29.

[26] N. Barrabés, J. Sá, Catalytic nitrate removal from water, past, present and future perspectives, Applied Catalysis B: Environmental, 104 (2011) 1-5.

[27] C. Franch, R.G.H. Lammertink, L. Lefferts, Partially hydrophobized catalyst particles for aqueous nitrite hydrogenation, Applied Catalysis B: Environmental, 156-157 (2014) 166-172.

[28] S.D. Ebbesen, B.L. Mojet, L. Lefferts, Effect of pH on the Nitrite Hydrogenation Mechanism over Pd/Al2O3 and Pt/Al2O3: Details Obtained with ATR-IR Spectroscopy, The Journal of Physical Chemistry C, 115 (2011) 1186-1194.

[29] J.K. Chinthaginjala, L. Lefferts, Support effect on selectivity of nitrite reduction in water, Applied Catalysis B: Environmental, 101 (2010) 144-149.

[30] K. Wada, T. Hirata, S. Hosokawa, S. Iwamoto, M. Inoue, Effect of supports on Pd-Cu bimetallic catalysts for nitrate and nitrite reduction in water, Catalysis Today, 185 (2012) 81-87.

[31] G. Strukul, R. Gavagnin, F. Pinna, E. Modaferri, S. Perathoner, G. Centi, M. Marella, M. Tomaselli, Use of palladium based catalysts in the hydrogenation of nitrates in drinking water: from powders to membranes, Catalysis Today, 55 (2000) 139-149.

[32] O.M. Ilinitch, F.P. Cuperus, L.V. Nosova, E.N. Gribov, Catalytic membrane in reduction of aqueous nitrates: operational principles and catalytic performance, Catalysis Today, 56 (2000) 137-145.

[33] K. Lüdtke, K.-V. Peinemann, V. Kasche, R.-D. Behling, Nitrate removal of drinking water by means of catalytically active membranes, Journal of Membrane Science, 151 (1998) 3-11. 
[34] R. Sander, Compilation of Henry's law constants (version 4.0) for water as solvent, Atmospheric Chemistry and Physics, 15 (2015) 4399-4981.

[35] N.A. Jarrah, J.G. van Ommen, L. Lefferts, Growing a carbon nano-fiber layer on a monolith support; effect of nickel loading and growth conditions, Journal of Materials Chemistry, 14 (2004) 1590.

[36] F.J. Derbyshire, A.E.B. Presland, D.L. Trimm, Graphite formation by the dissolution - precipitation of carbon in cobalt, nickel and iron, Carbon, 13 (1975) 111-113.

[37] S. Hörold, T. Tacke, K.-D. Vorlop, Catalytical removal of nitrate and nitrite from drinking water: 1. Screening for hydrogenation catalysts and influence of reaction conditions on activity and selectivity, Environmental Technology, 14 (1993) 931-939.

[38] I. Mikami, Y. Sakamoto, Y. Yoshinaga, T. Okuhara, Kinetic and adsorption studies on the hydrogenation of nitrate and nitrite in water using $\mathrm{Pd}$-Cu on active carbon support, Applied Catalysis B: Environmental, 44 (2003) 79-86.

[39] T.R. Marrero, E.A. Mason, Gaseous Diffusion Coefficients, Journal of Physical and Chemical Reference Data, 1 (1972) 3-118.

[40] M. Sadrzadeh, K. Shahidi, T. Mohammadi, Effect of operating parameters on pure and mixed gas permeation properties of a synthesized composite PDMS/PA membrane, Journal of Membrane Science, 342 (2009) 327-340.

[41] Y. Matatov-Meytal, Cloth catalysts in water denitrification III. pH inhibition of nitrite hydrogenation over Pd/ACC, Applied Catalysis B: Environmental, 45 (2003) 127-134. 


\section{Appendix A: Figures and graphs}
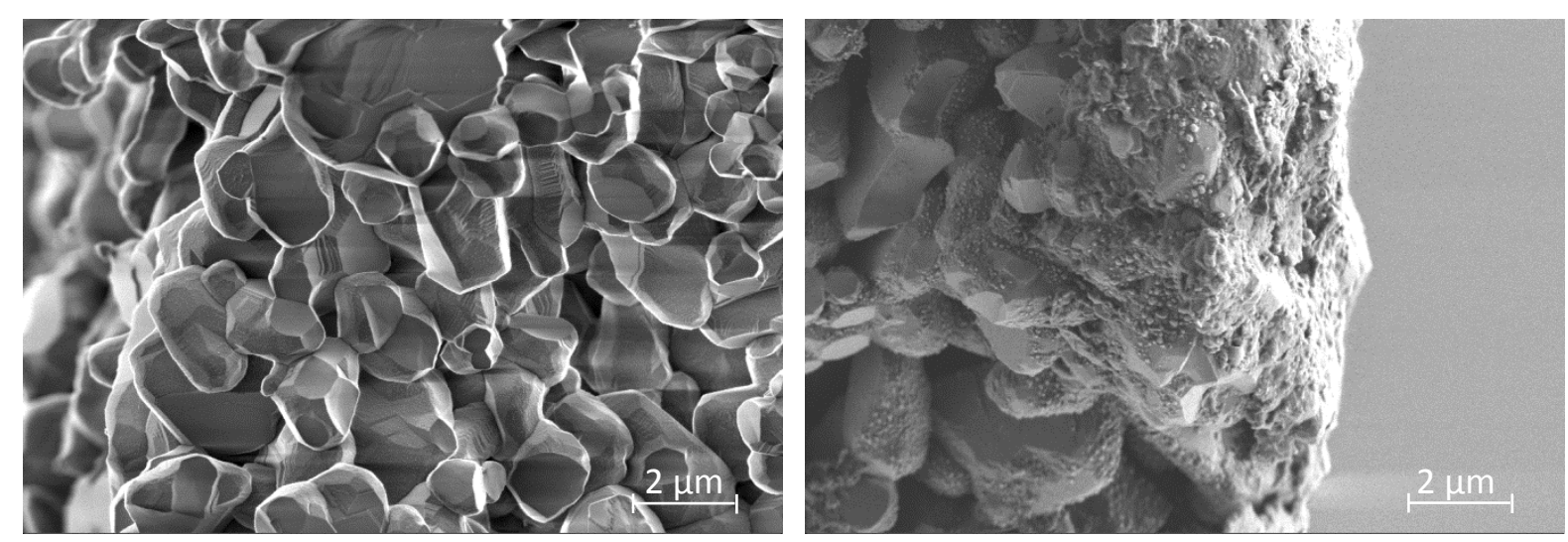

Figure A1: Cross-sectional view of the a) inner wall and b) outer wall of the sample prepared with 1.0 $\mathrm{gNi} / \mathrm{L}$, reduced at $850^{\circ} \mathrm{C}$ and with $\mathrm{CNFs}$ grown at $350^{\circ} \mathrm{C}$. Only the outer wall presents a layer of amorphous carbon. 


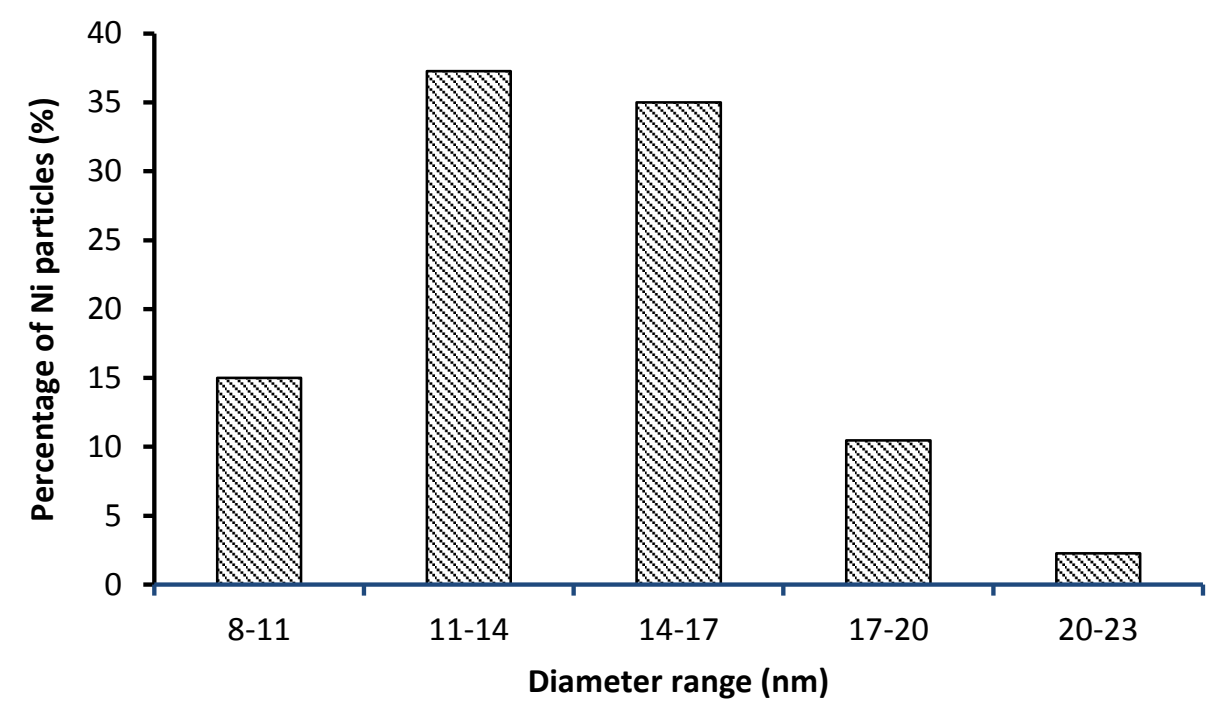

Figure A2: Nickel particle size distribution on the alumina hollow fiber after using $1.0 \mathrm{gNi} / \mathrm{L}$ and a reduction temperature of $850^{\circ} \mathrm{C}$

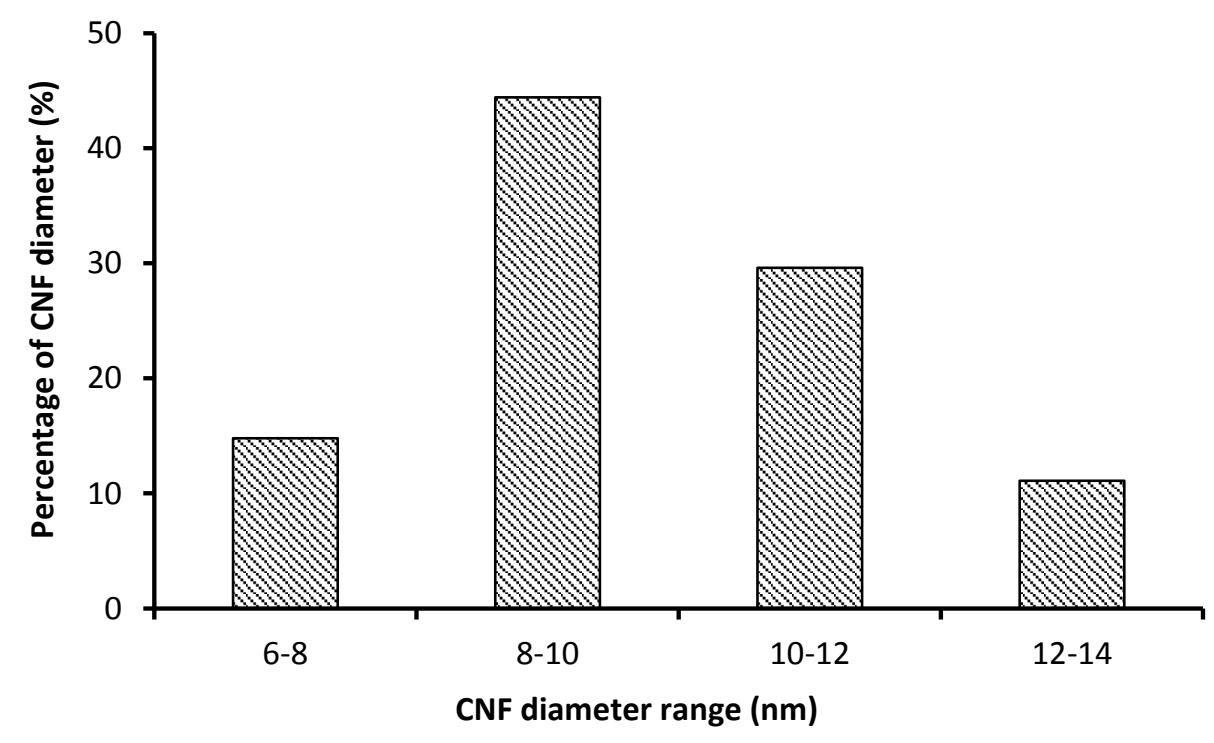

Figure A3: CNF diameter distribution on the alumina hollow fiber after using $1.0 \mathrm{gNi} / \mathrm{L}$, a reduction temperature of $850^{\circ} \mathrm{C}$ and a CNF growth temperature of $600{ }^{\circ} \mathrm{C}$ 

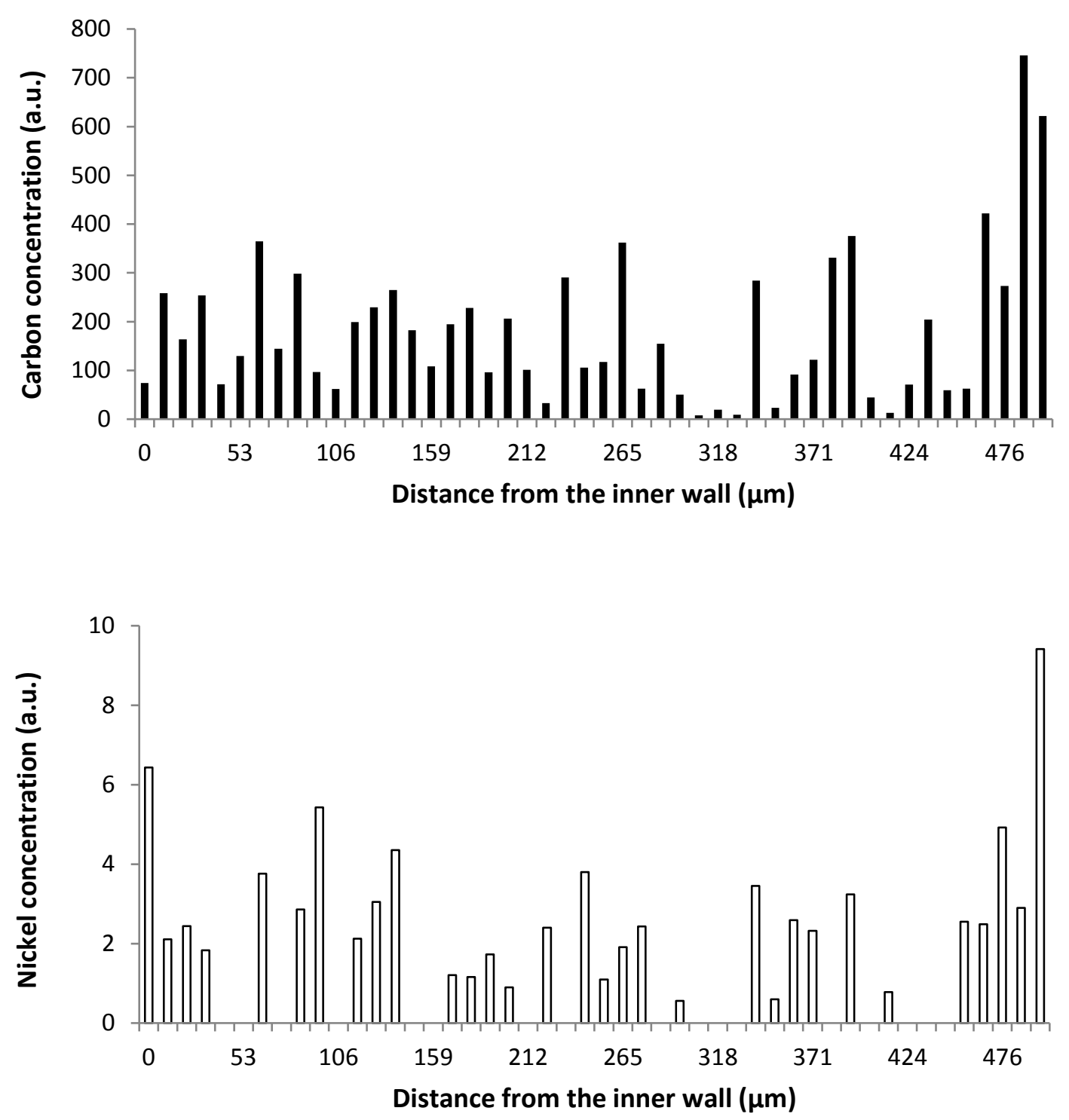

Figure A4: EDX measurements on a membrane cross-section for a) carbon distribution through the wall, b) nickel distribution through the wall. Scatter is caused by the roughness of the surface of the cross-section. 


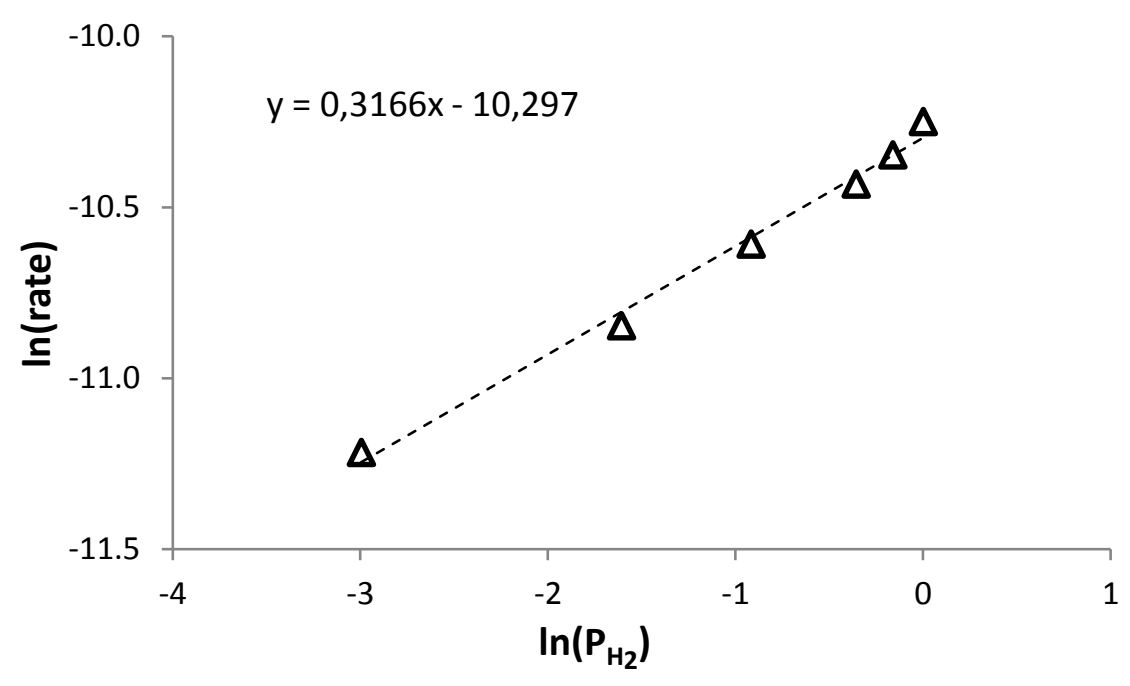

Figure A5: Effect of hydrogen partial pressure on the reaction rate. The slope of the regression line indicates a hydrogen reaction order of 0.3 


\section{Appendix B: Weisz-Prater criterion $\left(C_{w p}\right)$}

$\mathrm{C}_{\mathrm{wp}}$ was calculated for the 'Packed bed' layout (high flow rate) to estimate the presence of internal mass transfer limitations (equation 5$)$. $r_{\text {obs }}$ is the observed reaction rate $\left(\mathrm{mol} /\left(\mathrm{g}_{\mathrm{cat}}{ }^{*} \mathrm{~s}\right)\right)$. It was calculated from the liquid flow rate $(0.4 \mathrm{ml} / \mathrm{min})$, the average reactant concentration in the catalyst bed $(210$ $\left.\mu \mathrm{molNO}{ }_{2}^{-} / \mathrm{L}, 770 \mu \mathrm{molH}_{2} / \mathrm{L}\right)$, the conversion $\left(4.2 \mathrm{wt} \% \mathrm{NO}_{2}{ }^{-}\right.$and $\left.2.8 \mathrm{wt} \% \mathrm{H}_{2}\right)$ and the amount of supported catalyst $(0.43 \mathrm{~g}) . \rho_{\mathrm{p}}$ is the bulk density of the $\alpha$-alumina with the grown CNFs inside the alumina macropores $\left(\mathrm{g} / \mathrm{cm}^{3}\right)$. It was calculated from the porosity $(0.34)$ and density $\left(2.6 \mathrm{~g} / \mathrm{cm}^{3}\right)$ of the alumina and from the density $\left(2.15 \mathrm{~g} / \mathrm{cm}^{3}\right)$ and amount of CNFs $(7.5 \mathrm{wt} \%) . \mathrm{R}_{\mathrm{p}}$ is the radius of the supported catalyst particles $(0.025 \mathrm{~cm})$. $D_{A B}$ is the molecular diffusivity of nitrite $\left(1.91 * 10^{-5} \mathrm{~cm}^{2} / \mathrm{s}\right)$ or hydrogen $\left(5.11 * 10^{-5} \mathrm{~cm}^{2} / \mathrm{s}\right)$ in water $\left(\mathrm{cm}^{2} / \mathrm{s}\right) . \varepsilon$ and $\tau$ are the total porosity and tortuosity respectively. The total porosity was calculated from the alumina porosity $(0.34)$ and the density $\left(2.15 \mathrm{~g} / \mathrm{cm}^{3}\right)$ and amount of CNFs (7.5 wt\%). The total tortuosity was defined as 2, assuming that the presence of CNFs will not affect severely the tortuosity of the system since they offer an open structure. $C_{A}$ is the reactant concentration $\left(\mathrm{mol} / \mathrm{cm}^{3}\right.$ ). For $C_{w p} \ll<1$, internal mass transfer limitations can be excluded while for $C_{w p}$ >> 1, mass transfer limitations become significant and pronounced concentration gradients are stablished inside the catalyst particles. For $C_{w p}$ values close to 1 , mass transfer limitations cannot be excluded but are not dominant neither.

$C_{w p}=\frac{r_{o b s} * \rho_{p} * R_{p}{ }^{2}}{\frac{\varepsilon * D_{A} B_{*}}{\tau} * C_{A}}$

(Equation B1) 